\title{
Sifat Antioksidatif Ekstrak Kunir Putih (Curcuma mangga Val.) dengan Pelarut Aseton, Etanol atau Metanol
}

\author{
The Antioxidative Properties of White Saffron (Curcuma mangga Val.) Extracted with \\ Aceton, Ethanol or Methanol
}

\section{Dwiyati Pujimulyani}

Fakultas Teknologi Pertanian Universitas Wangsa Manggala Yogyakarta

Jl Wates Km 10 Argomulyo Pos Kemusuk Yogyakarta 55753, No. Telp: (0274) 798212 Fax : 0274798213

e-mail:dwiyati2002@yahoo.com

\begin{abstract}
A study on the antioxidative properties of white saffron extracted with aceton, ethanol or methanol was undertaken. The purpose of this research is to have a white saffron extract with a high antioxidant activity. White saffron rhizome was peeled, washed, grated, and added within either aceton, ethanol or methanol (white saffron : solvent = 1:3 or 1:4) (W/V) then stirred for 1 hour. The residue was washed with solvent in the same volume. The antioxidant activity of the extract was measured by Ferrythiocyanate (FTC) or Thio Barbituric Acid (TBA) methods. The result showed that the antioxidant activity of white saffron extracted with ethanol was higher than that with methanol, and aceton, respectively. The highest antioxidant activity was obtained from the extract of white saffron extracted with ethanol.
\end{abstract}

Key words : white saffron, aceton, ethanol, methanol, antioxidant activity

Diterima : 07 Mei 2005, disetujui : 10 Agustus 2005

\section{Pendahuluan}

Kunir putih (Curcuma mangga Val.) mengandung kurkuminoid $132 \mathrm{ppm}$. Tiga komponen kurkuminoid adalah kurkumin, demetoksi kurkumin dan bisdemetoksi kurkumin (Majeed et al., 1995, Tonnesen, 1986). Menurut Sudibyo (1996) kurkuminoid dalam kunyit $2,5 \quad-8,1 \%$ (bk). Ketiga komponen tersebut, sendiri-sendiri maupun bersama-sama menunjukkan potensi antioksidatif (Majeed et al., 1995; Cuvelier et al., 1992). Akan tetapi, sifat antioksidatif tersebut akan berkurang jika dipanaskan. Semakin tinggi suhu dan semakin lama waktu pemanasan, akan berakibat pada penurunan sifat antioksidatif yang juga semakin besar (Pujihartati, 1999).

Apabila Rimpang kunir putih yang diiris melintang menunjukkan pada bagian tepi berwarna putih kekuning-kuningan dan bagian tengah berwarna kekuningan. Aroma Rimpang kunir putih seperti bau buah mangga, sehingga masyarakat menyebutnya temu mangga (Fauziah, 1999). Kunir putih mengandung kurkuminoid (Dwiyati dan Sutardi, 2003) dan menurut Masuda et al., (1992); Masuda et al., (1993) kurkuminoid mempunyai potensi sebagai antioksidan. Sirup kunir putih mampu menghambat oksidasi dengan metode FTC dan TBA. Sirup kunir putih dengan perlakuan blanching asam sitrat selama lima menit mempunyai aktivitas antioksidan yang tinggi (Dwiyati, 2003).

Menurut Kizo et al. (1983) kurkuminoid dapat larut dalam aseton, etanol dan metanol, sehingga diduga kunir putih yang diekstrak dengan pelarut tersebut akan mempunyai aktivitas antioksidan. Penggunaan berbagai jenis pelarut sebagai pengekstrak bertujuan untuk mengetahui komponen antioksidan yang terekstrak dan dipilih aktivitas terbesar dari tiga 
jenis pelarut yaitu aseton, etanol atau metanol. Menurut Kikuzaki dan Nakatani (1993) untuk isolasi dan identifikasi komponen antioksidatif rimpang jahe digunakan etanol, sedangkan Duh dan Yen (1997) melakukan ekstraksi dengan pelarut metanol pada kedelai.

Berdasarkan fakta tersebut, maka dilakukan penelitian untuk mengetahui aktivitas antioksidasi ekstrak kunir putih dengan tiga jenis pelarut menggunakan metode FTC dan TBA.

\section{Metode Penelitian}

\section{Bahan dan Alat}

Bahan baku yang digunakan dalam penelitian ini adalah kunir putih yang diperoleh dari pasar Beringharjo, Yogyakarta. Adapun, bahan kimia untuk analisis menggunakan bahan Pro Analisis (PA) dari MERCK yaitu etanol, metanol dan aseton, asam linoleat, garam fosfat, $\mathrm{FeCl}_{2}$, amonium tiosianat, TBA, TCA, kloroform yang diperoleh dari laboratorium Pengolahan Hasil Pertanian, Fakultas Teknologi Pertanian UNWAMA dan laboratorium Kimia dan Biokimia, Fakultas Teknologi Pertanian, Universitas Gadjah Mada, Yogyakarta.

Alat yang digunakan dalam penelitian ini adalah spektrofotometer Shimadzu UV-1202 $\mathrm{V}$, oven, vortex, sentrifus, stirer dan neraca Sartorius.

\section{Cara Penelitian}

Kunir putih dibersihkan, dikupas, dicuci, dan kemudian diparut. Parutan kunir putih diekstraksi dengan mencampur pelarut berupa aseton atau etanol atau metanol (metode Hammershcmidt dan Patt (1978) modifikasi) dengan perbandingan (parutan:pelarut: $=1: 3$ dan 1:4 w/v). Campuran selanjutnya diaduk dengan menggunakan stirer selama satu jam, dan kemudian disaring sehingga didapatkan ekstrak 1. Residu ditambah pelarut dengan jenis dan volume sama, diaduk dengan distirer selama satu jam, kemudian disaring sehingga diperoleh ekstrak 2. Ekstrak 1 dan ekstrak 2 dicampur dan diukur aktivitas antioksidatifnya dengan metode FTC dan TBA.

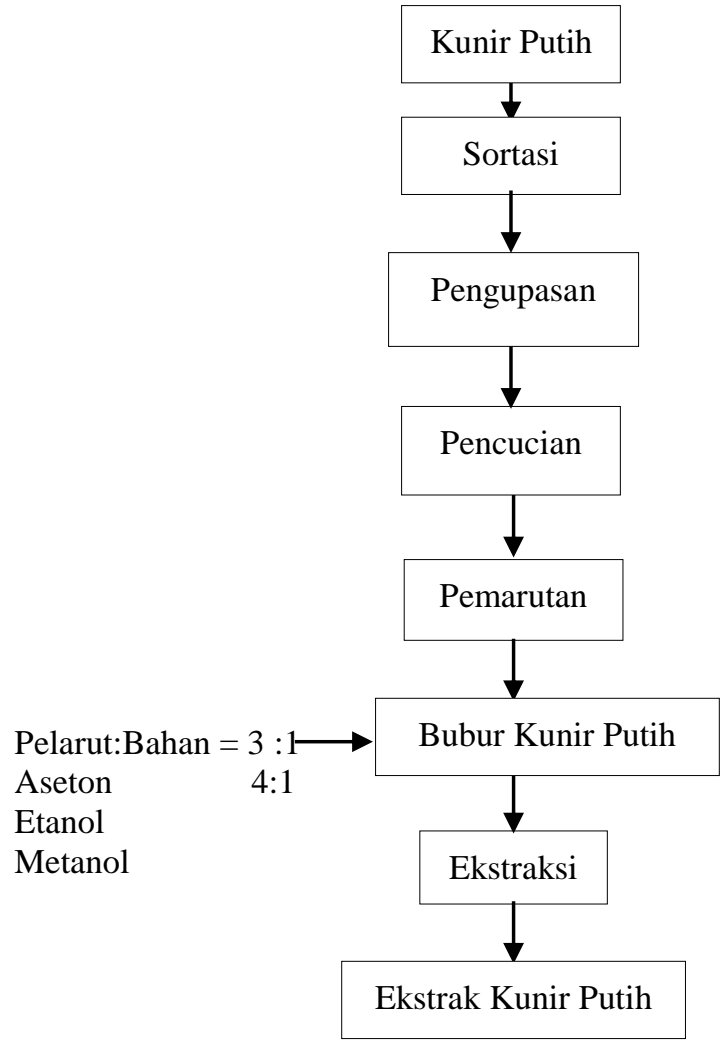

Gambar 1. Diagram alir ekstraksi kunir putih
Uji penghambatan oksidasi dalam sistem asam linoleat dengan metode: FTC dan TBA 
Pengujian terhadap ekstrak kunir putih meliputi: Pengujian aktivitas antioksidasi dengan Metode Ferri Tiosianat dan TBA. Nilai peroksida yang diukur dengan nilai absorbsi pada $\lambda 500 \mathrm{~nm}$ ditentukan dengan metode Ferri Tiosianat (Mitsuda et al., 1967 dan Osawa dan Namiki, 1981 dalam Kikuzaki dan Nakatani, 1993). Nilai Tiobarbituric Acid yang diukur dengan nilai absorbsi pada $\lambda 530 \mathrm{~nm}$ ditentukan dengan metode Ottolenghi, 1959 dalam Kikuzaki dan Nakatani (1993). Diagram alir penelitian disajikan pada Gambar 1 .
Hasil dan Pembahasan

\section{Aktivitas Antioksidasi Ekstrak Kunir Putih yang diekstraksi dengan Pelarut Aseton, Etanol atau Metanol dengan Metode FTC}

Hasil uji FTC ekstrak kunir putih dengan larutan pengekstrak aseton, etanol atau metanol disajikan pada Gambar 2 (perbandingan pelarut:bahan $=4: 1)(\mathrm{v} / \mathrm{w})$

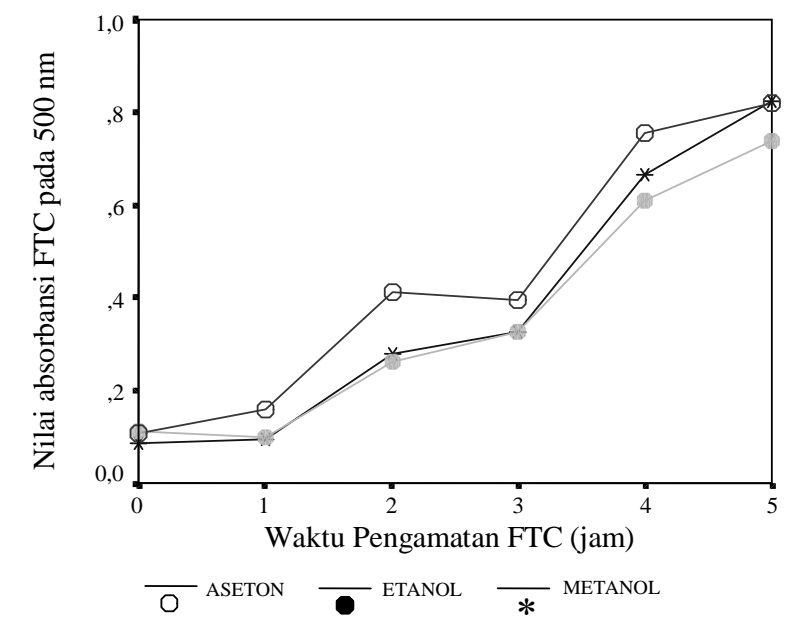

Gambar 2. Nilai FTC ekstrak kunir putih dengan pelarut aseton, etanol atau metanol dengan rasio pelarut : bahan $=4: 1(\mathrm{v} / \mathrm{w})$ (Rerata dari 2 batch, 3 ulangan analisis)

Gambar 2. menunjukkan bahwa ekstrak kunir putih dengan pelarut etanol dengan perbandingan pelarut: bubur kunir putih $=4: 1$ mempunyai aktivitas antioksidatif (daya hambat oksidasi) terbesar dalam sistem asam linoleat. Urutan yang mempunyai aktivitas antioksidatif lebih kecil yaitu ekstrak dengan pelarut metanol, kemudian yang terkecil adalah aseton. Menurut Jitoe et al., (1992) aktivitas antioksidatif kurkuminoid besarnya 2,5 kali lebih kuat dibanding $\lambda$-tokoferol. Hal ini juga dikemukakan oleh Revankar et al., (1975) dalam Majeed et al., (1995) bahwa aktivitas antioksidatif kurkuminoid sebagai aditif pangan, potensial untuk mencegah oksidasi minyak dan lemak selama penyimpanan atau pemanasan.

Hasil uji FTC ekstrak kunir putih dengan pelarut aseton, etanol atau metanol disajikan pada Gambar 3 (perbandingan pelarut:bahan = $3: 1)(\mathrm{v} / \mathrm{w})$. 


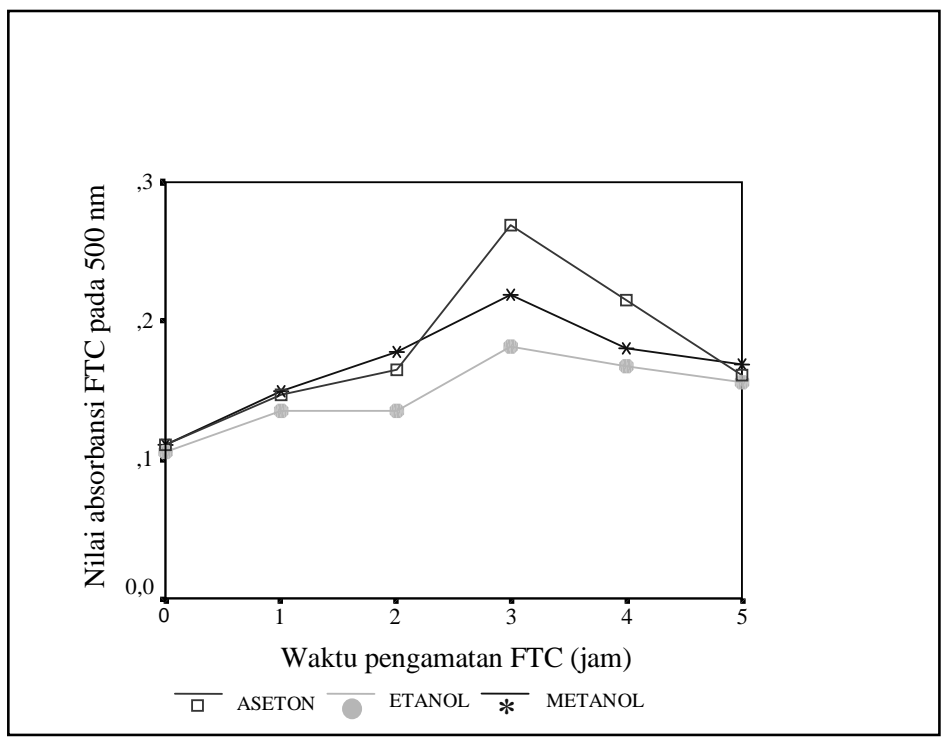

Gambar 3. Nilai FTC ekstrak kunir putih dengan pelarut aseton, etanol atau methanol dengan rasio pelarut:bahan $=3: 1$ (Rerata dari 2 batch, 3 ulangan analisis)

Pada Gambar 3. menunjukkan bahwa ekstrak kunir putih dengan pelarut etanol perbandingan pelarut:bubur kunir putih 3:1 mampu menghambat oksidasi asam linoleat terbesar. Pelarut metanol dapat menghasilkan ekstrak yang mempunyai daya hambat oksidasi lebih baik dari pada pelarut aseton. Hal ini diduga antioksidan yang terekstrak dengan baik dalam jumlah besar ke yang kecil dengan urutan pelarut etanol, metanol dan aseton. Adanya kemampuan menghambat oksidasi ini diduga karena ekstrak kunir putih mengandung kurkuminoid. Menurut
Pujihartati (1999) kurkuminoid dalam kunyit dapat menghambat oksidasi melalui penghambatan proses propagasi yang diukur dengan angka absorbansi $500 \mathrm{~nm}$ untuk menentukan nilai peroksida dan terminasi yang diukur dengan angka absorbansi pada $530 \mathrm{~nm}$ untuk menentukan malonaldehid. Pada Gambar 2 dan 3 menunjukkan bahwa ekstraksi dengan perbandingan pelarut:bahan $=3: 1 \quad(\mathrm{v} / \mathrm{w})$ mempunyai daya hambat lebih baik dibanding pelarut:bahan $4: 1(\mathrm{v} / \mathrm{w})$.

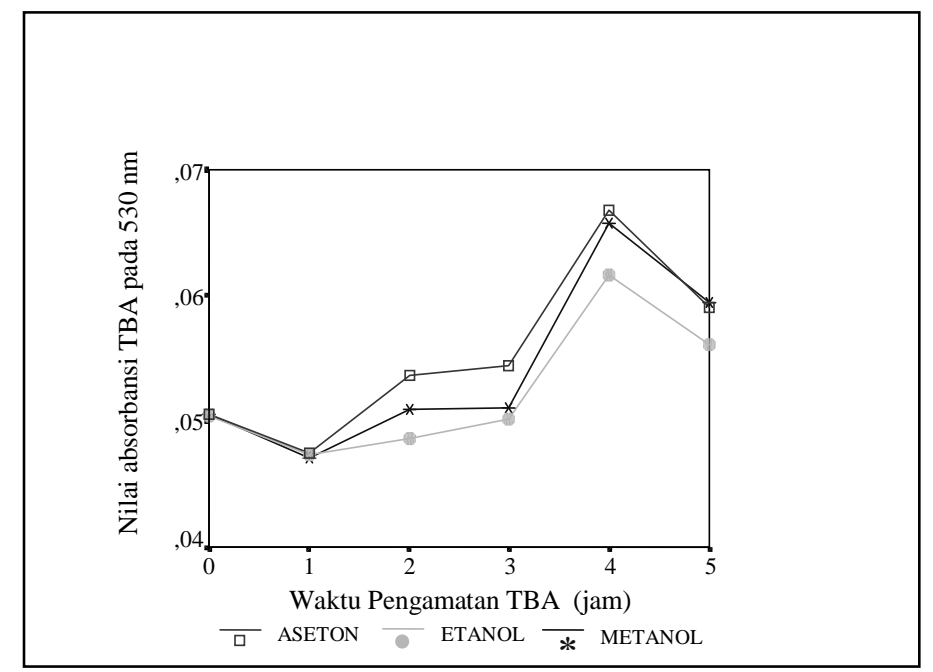

Gambar 4. Nilai MDA ekstrak kunir putih dengan berbagai pelarut aseton, etanol atau metanol (pelarut:bahan $=4: 1)$ (Rerata dari 2 batch, 3 ulangan analisis) 


\section{Aktivitas Antioksidatif Ekstrak Kunir Putih dengan Pelarut Aseton, Etanol atau Metanol (Metode TBA)}

Hasil uji TBA ekstrak kunir putih dengan larutan pengekstrak aseton, etanol atau metanol disajikan pada Gambar 4 (pelarut:bahan $=4: 1)(\mathrm{v} / \mathrm{w})$.

Pada Gambar 4 menunjukkan bahwa ekstrak kunir putih dengan berbagai pelarut menunjukkan mampu menghambat pembentukan MDA dengan urutan kemampuan dari yang besar ke yang kecil yaitu etanol, metanol dan aseton, sehingga diduga mengandung senyawa antioksidan.

Hasil uji TBA ekstrak kunir putih dengan larutan pengekstrak aseton, etanol dan metanol disajikan pada Gambar 5 (perbandingan pelarut:bahan $=3: 1)(\mathrm{v} / \mathrm{w})$.

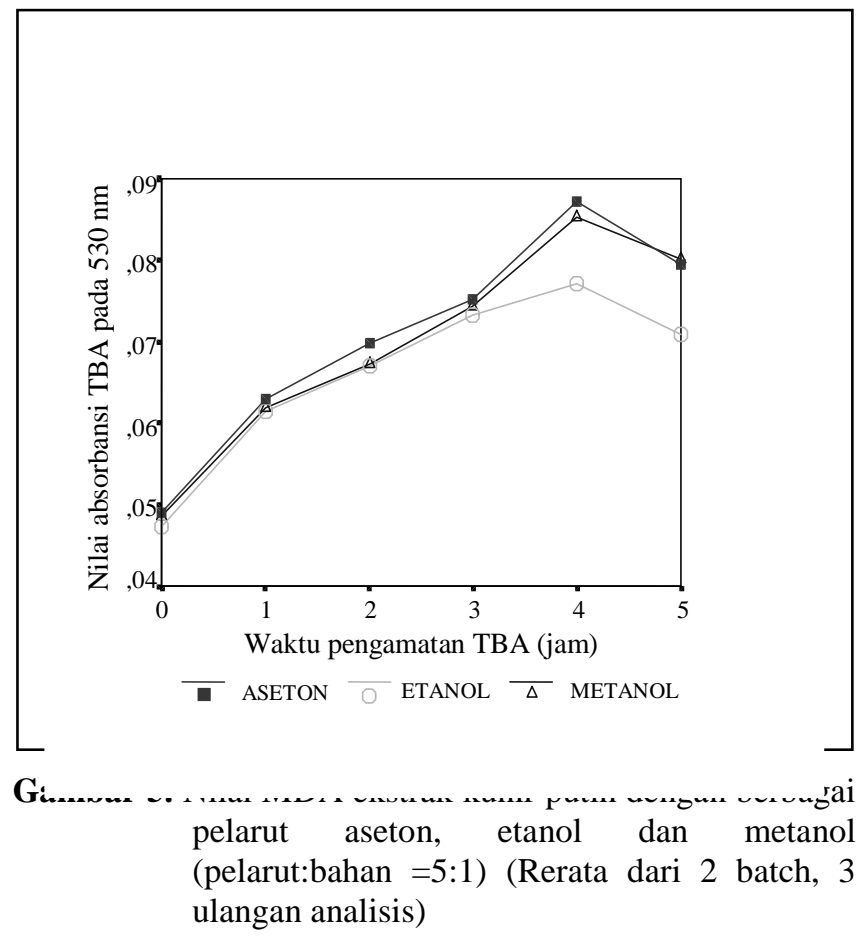

Gambar 5 menunjukkan kecenderungan yang sama dengan Gambar 4 yaitu ekstrak dengan pelarut etanol mempunyai daya hambat paling besar terhadap pembentukan MDA dalam sistem asam linoleat. Urutan yang mempunyai daya hambat dari yang besar ke yang kecil adalah pelarut etanol, metanol dan aseton. Hal ini diduga antioksidan kunir putih dapat terekstrak dengan baik pada etanol, metanol dan kurang baik dengan pelarut aseton.

\section{Kesimpulan dan Saran}

Kesimpulan umum dari penelitian ini adalah dapat dihasilkan ekstrak kunir putih yang mempunyai aktivitas antioksidan tinggi dengan pelarut etanol.
Kesimpulan khusus yang mendukung kesimpulan umum yaitu:

1. Urutan ekstrak kunir putih yang mempunyai aktivitas antioksidan dari tinggi ke rendah yang diekstrak dengan pelarut etanol, metanol dan aseton.

2. Pelarut etanol dapat menghasilkan ekstrak kunir putih dengan sifat antioksidatif yang paling tinggi dibanding pelarut yang lain dalam penelitian ini.

Saran pada penelitian ini adalah perlu dilakukan penelitian dengan membandingkan antioksidan sintetis yang sudah beredar di pasaran sehingga dapat diketahui secara pasti kemampuan penghambatan oksidasi ekstrak kunir putih jika dibandingkan dengan antioksi dan sintetis. 


\section{Ucapan Terima Kasih}

Penulis mengucapkan terimakasih atas bantuan dana tahun 2004 dari Yayasan WANGSA MANGGALA YOGYAKARTA, sehingga penelitian dapat berjalan lancar.

\section{Daftar Pustaka}

Cuvelier, M.E., Richard, dan Berse T.C. 1992. Camparison of the Antioxidative Activity of Some Acid-phenols: Structure-Activity Relationship. Biosci. Biotech.Biochem, 56:324-326.

Duh, P.D. dan Yen, G-C. 1997. Antioxidant Efficacy of Methanolic Extract of Peanut Hulls in Soybean and Peanut Oils, JAOCS, Vol 74, No. 6.

Dwiyati P. 2003. The Effect of Blanching on Antioxidant Properties of White Saffron Syrup (Curcuma mangga Val) Agritech, vol 23, No 3 D; 137 141.

Dwiyati P. dan Sutardi, 2003. Curcuminoid Content and Antioxidative Properties on White Saffron Extract (Curcuma mangga Val), Proceeding International Conference on redesigning Sustainable Development on Food and Agricultural System for Developing Countries. Fac. of Agricultural Technology, Gadjah Mada University.

Fauziah, 1999. Temu-temuan dan Empon-empon, Budidaya dan Manfaatnya. Kanisius. Yogyakarta

Jitoe, A., Matsuda, T., Tengah, I.G.P., Suprapta, D.N., Gara, I.W. dan Nakatami, N. 1992. Antioxidan Activity of Tropical Ginger Extracts and Analysis of the Contained Curcuminoids. J. Agric. Food Chem. 40:13371340.
Kikuzaki, H. dan Nakatani, N. 1993. Antioxidant Effects of Some Ginger Constituents. J. Food Sci. 58:1407-1410.

Kizo, J., Suzaki, Y., Wahmahe, N., Oshima, Y. and Kikino, H. 1983 Antihepatotoxic, Principles of Curcuma longa Rhizomes, Plan, Reas, Medica, 49:185-187.

Majeed, M., Vladimir, B., Uma, S. dan Rajendran, R. 1995. Curcumeinoids Antioxidant Phytonutriens. Nutriscience. Publ. Inc. Piscataway, New Jersey.

Masuda, T., Isobe, J., Jitoe, A. dan Nakatani, N. 1992. Antioxidative Curcuminoids from Rhizomes of Curcuma Xanthorrhiza, Phythocem. 31 (10): 3645-3647.

Masuda, T., Jitoe, A., Isobe, J., Nakatani, N. dan Yonemori, S. 1993. Antioxidative and Anti Inflammatory Curcumin-Related Phenolics from Rhizomes of Curcuma domestica, Phytochem, 32(6): 1557-1560.

Mitsuda, H., Yasumoto, K. dan Iwami, K. 1967. Antioxidative Action of Indole Compounds during the Autoxidation of Linoleic Acid, Eiyoto Sokuryou 19(3):210.

Pudjihartati, V.L. 1999. Stabilitas Atioksidan Ekstrak Kunyit (Curcuma domestica) selama Penyimpanan Umbi dan Pemanasan, Tesis S2 Fak. Teknik Pertanian, UGM, Yogyakarta.

Sudibyo, M. 1996. Penentuan Kadar Kurkuminoid secara KLT-Densitometri. Buletin ISKI, 2:11-21.

Tonnesen, H.H. 1986. Chemistry, Stability and Analysis of Curcumin A Naturally Recuiring Drug Moleclue, Ph.D. Thesis Institute of Pharmacy, University of Oslo. Oslo. 